\title{
Selective Hydrogenation of Benzofurans Using Ruthenium Nanoparticles in Lewis Acid-Modified Ruthenium-Supported lonic Liquid Phases
}

Sami El Sayed, Alexis Bordet, Claudia Weidenthaler, Walid Hetaba, Kylie L. Luska, and Walter Leitner*

Cite This: ACS Catal. 2020, 10, 2124-2130

Read Online

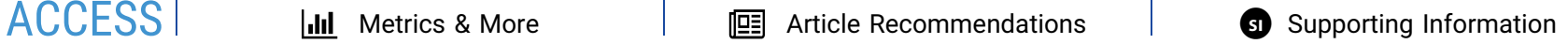

ABSTRACT: Ruthenium nanoparticles immobilized on a Lewisacid-functionalized supported ionic liquid phase ( $\mathrm{Ru} @$ SILP-LA) act as effective catalysts for the selective hydrogenation of benzofuran derivatives to dihydrobenzofurans. The individual components (nanoparticles, chlorozincate-based Lewis-acid, ionic liquid, support) of the catalytic system are assembled using a molecular approach to bring metal and acid sites in close contact

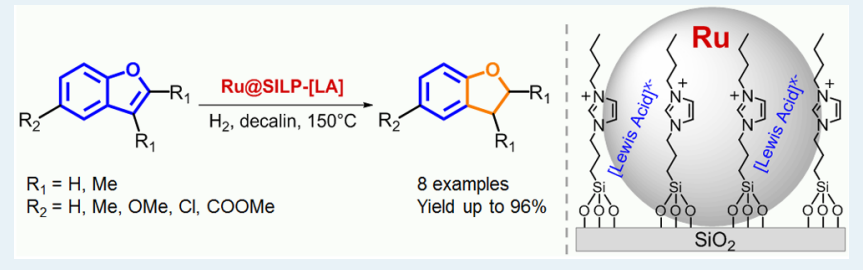
on the support material, allowing the hydrogenation of $\mathrm{O}$ containing heteroaromatic rings while keeping the aromaticity of C6-rings intact. The chlorozincate species were identified to be predominantly $\left[\mathrm{ZnCl}_{4}\right]^{2-}$ anions using X-ray photoelectron spectroscopy and are in close interaction with the metal nanoparticles. The Ru@SILP- $\left[\mathrm{ZnCl}_{4}\right]^{2-}$ catalyst exhibited high activity, selectivity, and stability for the catalytic hydrogenation of a variety of substituted benzofurans, providing easy access to biologically relevant dihydrobenzofuran motifs under continuous flow conditions. KEYWORDS: supported ionic liquid phases, ruthenium nanoparticles, Lewis acid, selective benzofurans hydrogenation, continuous flow

\section{INTRODUCTION}

The catalytic reduction of functional groups (alkene, carbonyl, imine, nitro, etc.) in the side chains of aromatic substrates has attracted considerable attention in the past decade for the production of aromatic structures in the chemical industry, and especially in commodities, fine chemicals, agrochemicals, and pharmaceuticals. ${ }^{1-7}$ The selective hydrogenation of bicyclic heteroaromatic compounds (quinolines, indoles, benzopyrans, benzofurans, etc.) is especially attractive because of the presence of these motifs in various natural products, bioactive molecules, and pharmaceuticals. ${ }^{3-5,8,9}$ Whereas the catalytic hydrogenation of $\mathrm{N}$-containing bicyclic heteroaromatics has been widely studied, ${ }^{3,4,9-12}$ the development of catalysts able to efficiently and selectively hydrogenate O-containing heteroaromatics remains a challenge. ${ }^{2-4,8,11,13}$ Methods providing access to the dihydrobenzofuran motifs are however highly desirable, as these structures are key building blocks for the production of molecules possessing antioxidant, ${ }^{14-16}$ antibacterial, $^{15,17}$ anti-inflammatory, ${ }^{15,18}$ and cytotoxic ${ }^{15,19,20}$ activities (Scheme 1).

The selective hydrogenation of benzofurans to dihydrobenzofuran derivatives requires the use of specific catalysts possessing the ability to hydrogenate the furan ring while leaving the six-membered aromatic ring untouched. In this context, recent efforts led to the development of a few catalytic systems with promising activity. ${ }^{1-5,8,10,13}$ Notably, Dyson et al. reported the synthesis of Rh nanoparticles (NPs) in a Lewis acidic ionic liquid and their use for the hydrogenation of various heteroaromatics including a limited selection of benzofurans. ${ }^{5}$ In general, however, state-of-the-art catalysts for this reaction still show severe limitations such as low hydrogenation selectivity, ${ }^{2}$ narrow substrate scope, ${ }^{2-5,13,21,22}$ low stability, ${ }^{3,5,13}$ or are not suitable for continuous flow applications. $^{2-5,13,21,22}$

To address this synthetic challenge, we describe in this paper the preparation, characterization, and application of a new multifunctional catalyst system for the selective hydrogenation of benzofuran derivatives. Ruthenium NPs were combined with a Lewis acid-functionalized ionic liquid on a solid support using a molecular approach to assemble the individual key components of the active material in a flexible and controlled manner. Our approach is based on the deposition of welldefined NPs from organometallic precursors directly on ionic liquid-type layers that are covalently grafted on silica supports (supported ionic liquid phases, SILPs). This method allows to generate multifunctional catalytic systems with tailor-made reactivity. ${ }^{5,7,23-29}$ In this study, we present a version of such materials where ruthenium NPs are stabilized on a SILP consisting of an imidazolium-based Lewis acidic ionic liquid covalently grafted on silica. The resulting material is denoted $\mathrm{Ru} @$ SILP-LA, in which Ru defines the metal, SILP the ILgrafted silica, and LA the Lewis acidic species (Figure 1). The

Received: November 26, 2019

Revised: January 10, 2020

Published: January 22, 2020 
Scheme 1. Selective Partial Hydrogenation of Bicyclic Heteroaromatics: (a) N-Containing Substrates, (b) Benzofuran Derivatives: Goal of This Study, (c) Examples of Bioactive Molecules Containing the Dihydrobenzofuran Motif

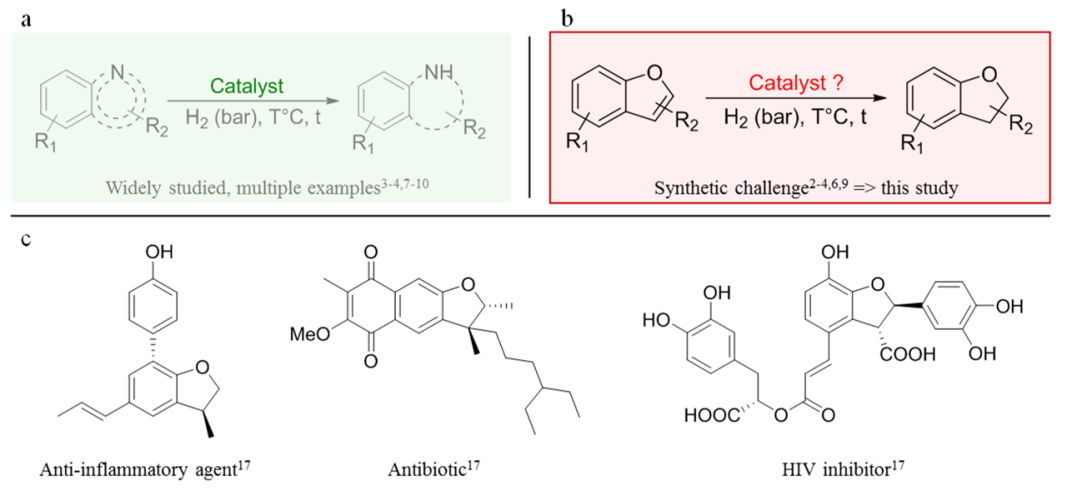

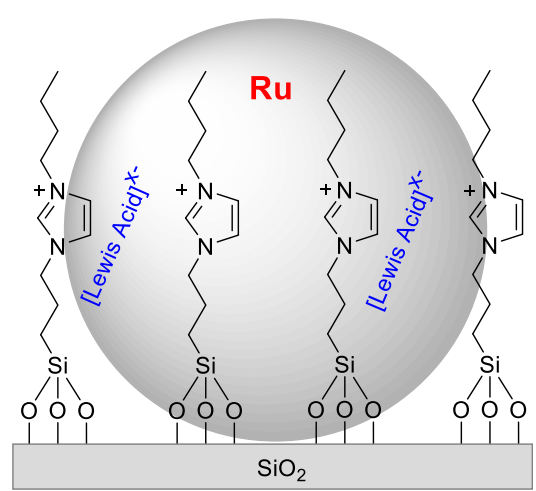

Figure 1. Schematic representation of the multifunctional catalysts based on ruthenium NPs on a Lewis acidic-supported ionic liquid phase (Ru@SILP-LA)

materials proved highly active and selective for the hydrogenation of a wide range of substrates bearing a variety of functionalities and showed excellent stability under continuous flow conditions.

\section{RESULTS AND DISCUSSION}

Synthesis of the Catalyst. The SILP-LA support material was synthesized via a two-step procedure involving first the condensation of a silane-functionalized imidazolium IL, [1butyl-3-(3-triethoxysilylpropyl)imidazolium] Cl, on dehydroxylated silica to form the corresponding SILP-Cl following an established procedure (see Supporting Information, Scheme S1). ${ }^{6}$ In a second step, SILP-LA was obtained through impregnation with $\mathrm{ZnCl}_{2}$ (0.74 equivalents relative to the IL loading). The synthesis of Ru NPs on SILP-LA was performed following previously reported procedures. ${ }^{26,30,31}$ This involved the wet impregnation of SILP-LA with a solution of $[\mathrm{Ru}(2$ methylallyl $\left.)_{2}(\operatorname{cod})\right]$ in dichloromethane. After removal of the solvent in vacuo, the impregnated SILP-LA was heated at 100 ${ }^{\circ} \mathrm{C}$ under an atmosphere of $\mathrm{H}_{2}$ (100 bar) for $18 \mathrm{~h}$. Upon subjection to the reductive environment, the color of the material turned from white to gray (see Supporting Information, Scheme S2).

Characterization. Solid-state ${ }^{29} \mathrm{Si}$ NMR of SILP-LA (Figure S1) shows the presence of two types of Si species: (1) tetrafunctionalized (Q) signals at $-109 \mathrm{ppm}\left(\mathrm{Q}_{4}=\right.$ $\left.\mathrm{Si}(\mathrm{OSi})_{4}\right)$ and $-102 \mathrm{ppm}\left(\mathrm{Q}_{3}=\mathrm{Si}(\mathrm{OSi})_{3} \mathrm{OH}\right)$; and $(2)$ trifunctionalized signals at $-58 \mathrm{ppm}\left(\mathrm{T}_{2}=\mathrm{R}-\mathrm{Si}(\mathrm{OSi})_{2} \mathrm{OR}^{\prime}\right)$ and $-53 \mathrm{ppm}\left(\mathrm{T}_{1}=\mathrm{R}-\mathrm{Si}(\mathrm{OSi})\left(\mathrm{OR}^{\prime}\right)_{2}\right)$. The $\mathrm{T}_{2}$ and $\mathrm{T}_{1}$ signals correspond to the $\mathrm{Si}$ atoms of IL bound to the $\mathrm{SiO}_{2}$ surface and thus provide evidence for the covalent attachment of the IL on the silica support. Transmission IR spectroscopy showed bands for the $\mathrm{C}-\mathrm{H}$ stretch of the imidazolium and aliphatic moieties (3145 and $2955 \mathrm{~cm}^{-1}$ ) and the symmetric ring stretch of the imidazolium ring (1560 and $1450 \mathrm{~cm}^{-1}$ ) (Figure S2). The presence of Lewis acid sites on SILP-LA was probed using pyridine-DRIFT-IR, which evidenced the characteristic band at $1630-1600 \mathrm{~cm}^{-1}$ (Figure S3).

The Ru loading on Ru@SILP-LA was determined to be 0.02 $\mathrm{mmol} / \mathrm{g}(0.20 \mathrm{wt} \%)$ by inductively coupled plasma atomic absorption spectroscopy (ICP-AAS), well in agreement with the theoretical value. The Brunauer-Emmett-Teller (BET) surface of the support does not change upon Ru-loading (Table S1). Analysis of the $\mathrm{Ru} 3 \mathrm{~d}$ region in the $\mathrm{X}$-ray photoelectron spectroscopy (XPS) spectra indicate that the Ru NPs are in the metallic state (BE Ru $3 \mathrm{~d}_{5 / 2}=280.5 \mathrm{eV}$; Figure $\mathrm{S}$ 4). Analysis of Ru@SILP-LA by scanning transmission electron microscopy with high-angle annular dark-field (STEMHAADF) shows that the NPs are small $(1.9 \mathrm{~nm})$ and welldispersed within the SILP (Figure 2a). Low-magnification STEM-HAADF-energy-dispersive X-ray (EDX) elemental mapping confirms that the ionic liquid is homogeneously

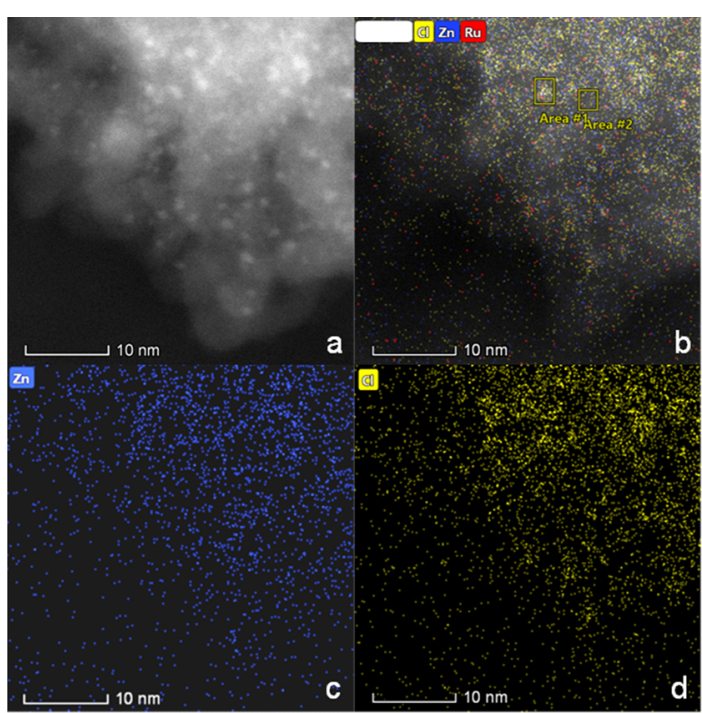

Figure 2. (a) STEM-HAADF and (b) EDX elemental mapping (STEM-HAADF-EDX) of Ru@SILP-LA, (c) $\mathrm{Zn}$ and (d) Cl elemental mapping. 

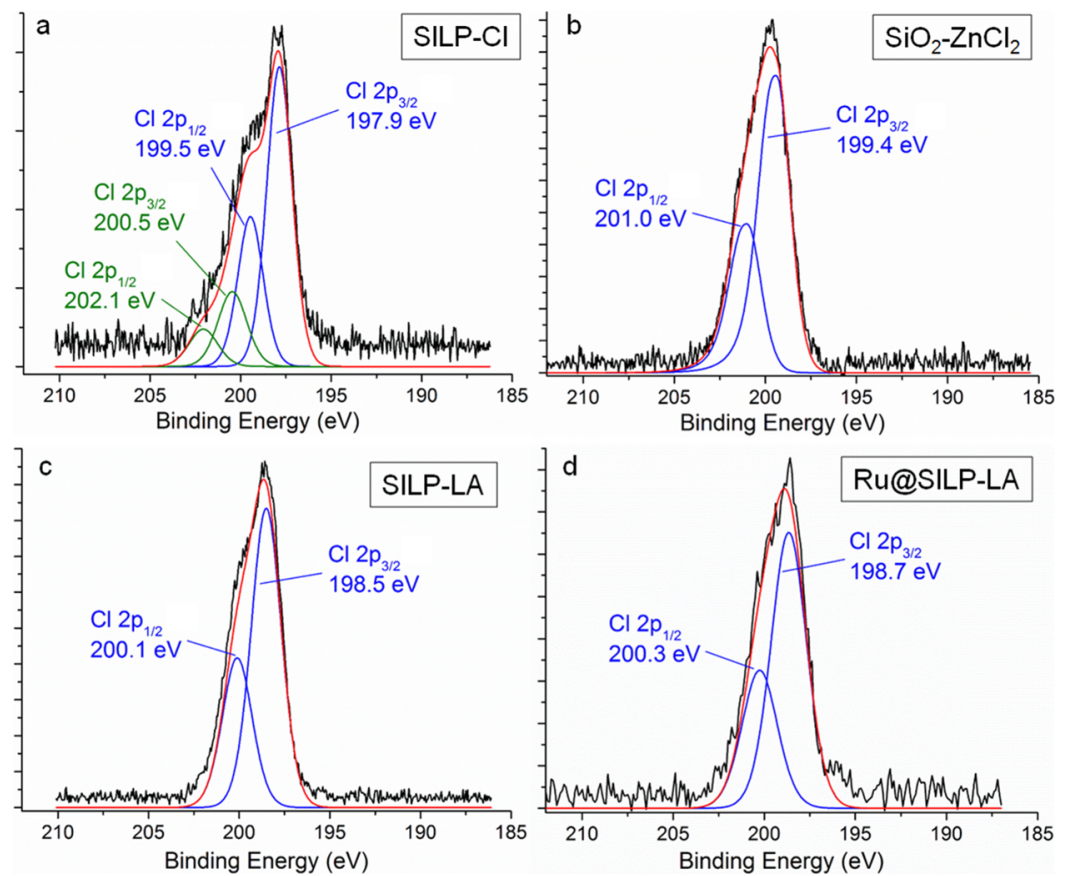

Figure 3. XPS-spectra of the $\mathrm{Cl} 2 \mathrm{p}$ region for (a) SILP-Cl, (b) $\mathrm{SiO}_{2}-\mathrm{ZnCl}_{2}$, (c) SILP-LA, and (d) $\mathrm{Ru@SILP-LA}$.

present on the support (Figure S5). Interestingly, STEMHAADF-EDX (Figures $2 b-d$ and S6) indicates that the concentration of $\mathrm{Zn}$ and $\mathrm{Cl}$ is about twofold higher around the $\mathrm{Ru} \mathrm{NPs}$ than in the NP-free regions, suggesting a strong interaction between the chlorozincate anions and the metal particles.

Although the use of Lewis acidic ionic liquids ${ }^{5,33}$ and the dynamic equilibria controlling the anionic speciation of chlorozincate anions $\left[\mathrm{Zn}_{x} \mathrm{Cl}_{2 x+2}\right]^{2-}$ in pure ionic liquid has been well studied, ${ }^{34}$ there are currently no reference data for SILP materials. Therefore, SILP-LA and Ru@SILP-LA were characterized by XPS, with a focus on the $\mathrm{Cl} 2 p$ region to investigate the nature of the chlorozincate anion(s) (Figure 3).

XPS spectra for the starting SILP-Cl and for $\mathrm{SiO}_{2}$ impregnated with $\mathrm{ZnCl}_{2}$ (denoted $\mathrm{SiO}_{2}-\mathrm{ZnCl}_{2}$ ) are provided as references to support the discussion. The $\mathrm{Cl} 2 \mathrm{p}$ spectrum of the starting SILP-Cl (Figure 3a) evidences the presence of a major $\mathrm{Cl}$ species (197.9 and $199.5 \mathrm{eV}$; Figure 3a), together with traces of a second species (200.5 and $202.1 \mathrm{eV}$ ) probably corresponding to nongrafted ionic liquid remaining after the washing step. In contrast, only one $\mathrm{Cl}$ species is visible after impregnation of the SILP-Cl with $\mathrm{ZnCl}_{2}$ to produce SILP-LA (Figure $3 \mathrm{c}$ ). The binding energies of $\mathrm{Cl} 2 \mathrm{p}_{3 / 2}$ and $2 \mathrm{p}_{1 / 2}$ in SILP-LA (198.5 and $200.1 \mathrm{eV}$ respectively) are significantly different from those observed for SILP-Cl (197.9 and 199.5 $\mathrm{eV}$; Figure 3a) and $\mathrm{SiO}_{2}-\mathrm{ZnCl}_{2}$ (199.4 and $201.0 \mathrm{eV}$; Figure $3 \mathrm{~b})$, suggesting the formation of a Cl-containing species different from $\mathrm{Cl}^{-}$and $\mathrm{ZnCl}_{2}$. The same species is observed after deposition of the Ru NPs (Ru@SILP-LA; Figure 3d). Based on previous literature reports by Licence et al., these data strongly suggest the presence of $\left[\mathrm{Zn}^{\mathrm{II}} \mathrm{Cl}_{4}\right]^{2-}$ anions on SILP-LA and Ru@SILP-LA. ${ }^{34}$ This hypothesis is further supported by the elemental analysis (ICP-AAS) which gives $\mathrm{Zn} / \mathrm{Cl}, \mathrm{N} / \mathrm{Cl}$, and $\mathrm{Zn} / \mathrm{N}$ molar ratios of ca. 1/4, 1/1, and 1/4, respectively (see Table $\mathrm{S} 1$ for details). Based on these results, the M@SILP-LA synthesized here can be formulated as a Ru@ SILP- $\left[\mathrm{ZnCl}_{4}\right]^{2-}$ material which exhibits Lewis acidity.
However, the presence of small quantities of free $\mathrm{Cl}^{-}$and Lewis acidic $\left[\mathrm{Zn}_{2} \mathrm{Cl}_{6}\right]^{2-}$ species on the catalyst is possible, as these anions were reported to exist in equilibrium with $\left[\mathrm{ZnCl}_{4}\right]^{2-34-36}$ These species are not visible by XPS, but this can be due to their low concentration and/or to the time scale of the equilibria between anions, which is faster than the XPS measurement. ${ }^{34}$ We thus do not exclude that small amounts of $\left[\mathrm{Zn}_{2} \mathrm{Cl}_{6}\right]^{2-}$ can contribute significantly to the Lewis acidity of the catalyst.

Interestingly, changing the amount of $\mathrm{ZnCl}_{2}$ introduced in the impregnation step $(0.50 / 0.67 / 0.74$ equiv relative to the ionic liquid) influenced neither the nature of the chlorozincate species formed (XPS) nor the $\mathrm{Zn}$ and $\mathrm{Cl}$ content (ICP-AAS) on the material (Table S2), suggesting that after the formation of $\left[\mathrm{Zn}^{\mathrm{II}} \mathrm{Cl}_{4}\right]^{2-}$ on the SILP, the remaining $\mathrm{ZnCl}_{2}$ does not react further and is removed during the washing step. This is in contrast with the case of pure ionic liquids, where the chemical structure of the anion $\left[\mathrm{Zn}^{\mathrm{II}}{ }_{n} \mathrm{Cl}_{2 n+2}\right]^{2-}$ is tunable and directed by the stoichiometric ratio of the ionic liquid and $\mathrm{ZnCl}_{2}$. ${ }^{34}$

Catalytic Study. The catalytic properties of Ru@SILP$\left[\mathrm{ZnCl}_{4}\right]^{2-}$ were first investigated in batch conditions using benzofuran (1) as a model substrate (Figure 4).

The substrate (benzofuran 1) was completely converted after $8 \mathrm{~h}$, producing dihydrobenzofuran (1a) in high yield $(88 \%)$, which was essentially retained over the course of the reaction. Compounds $\mathbf{1 b}$ and $\mathbf{1 c}$ were identified as minor byproducts. The amount of $\mathbf{1 b}$-which resulted from the full hydrogenation of the substrate-remained below $5 \%$ even at prolonged reaction time, demonstrating a very effective suppression of the aromatic hydrogenation by the Lewis acid modification. 1c was formed from $\mathbf{1}$ and/or $\mathbf{1 a}$ through hydrogenolysis, a transformation frequently observed in hydrogenation reactions catalyzed by transition-metal NPs. ${ }^{37,38}$ Based on these promising preliminary results, the catalyst's activity and stability were studied under continuous flow conditions (Figure 5). Continuous flow experiments involved passing a solution of benzofuran ( $0.05 \mathrm{M}$ in decalin) 

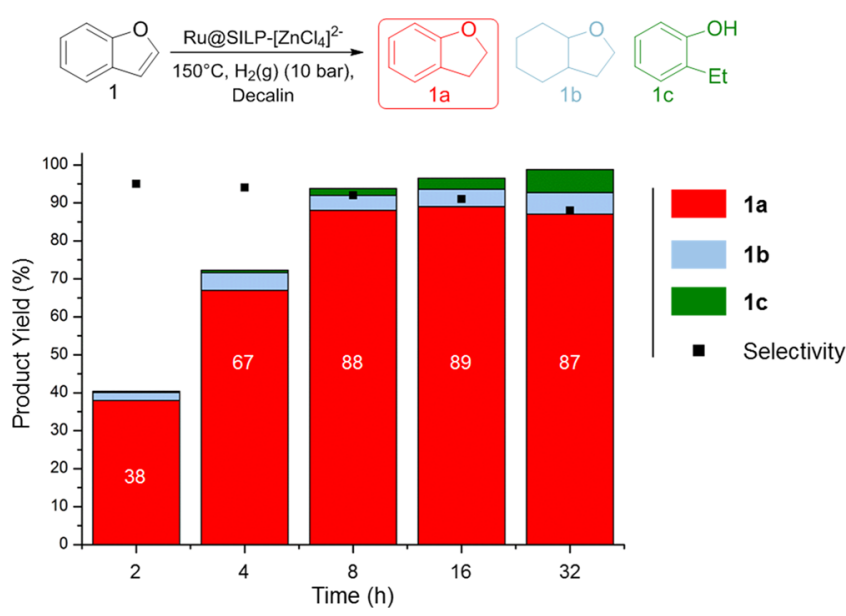

Figure 4. Reaction/time-profile for the hydrogenation of benzofuran (1) using $\mathrm{Ru} @ S I L P-\left[\mathrm{ZnCl}_{4}\right]^{2-}$. Reaction conditions: Ru@SILP$\left[\mathrm{ZnCl}_{4}\right]^{2-}(75 \mathrm{mg}, 0.00224 \mathrm{mmol})$, substrate $(1.68 \mathrm{mmol}, 750$ equiv), decalin $(0.5 \mathrm{~mL}), \mathrm{H}_{2}(10 \mathrm{bar}), 150{ }^{\circ} \mathrm{C}$. Composition of the reaction mixture determined by $\mathrm{GC}$ using tetradecane as an internal standard.

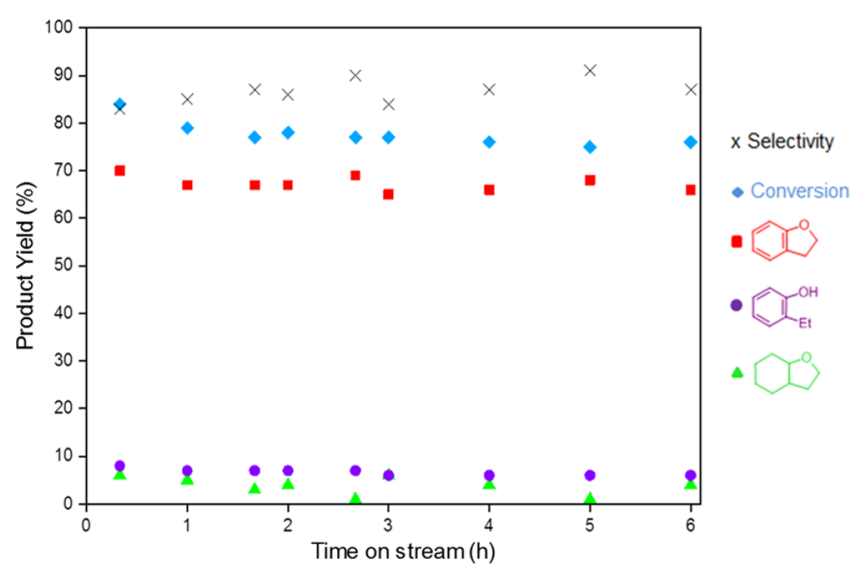

Figure 5. Hydrogenation of benzofuran $(0.05 \mathrm{M}$ in decalin, $0.5 \mathrm{~mL}$. $\mathrm{min}^{-1}$, residence time $\left.=1 \mathrm{~min}\right)$ using Ru@SILP- $\left[\mathrm{ZnCl}_{4}\right]^{2-}(537 \mathrm{mg}$, $0.016 \mathrm{mmol} \mathrm{Ru}$ ) under continuous flow conditions at $175^{\circ} \mathrm{C}$ and 10 bar $\mathrm{H}_{2}$ (gas flow rate $=35 \mathrm{~N} \mathrm{~mL} \cdot \mathrm{min}^{-1}$ ). Product composition and yields were determined by GC using tetradecane as an internal standard.

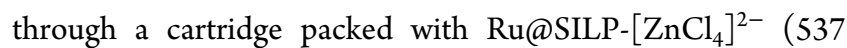
$\mathrm{mg}$ ) using a $\mathrm{H}$-Cube Pro from ThalesNano. The influence of the reaction temperature, substrate flow and $\mathrm{H}_{2}$ pressure on the catalytic activity and selectivity was investigated, whereas the hydrogen flow rate was maintained at $35 \mathrm{~N} \mathrm{~mL} \cdot \mathrm{min}^{-1}$. After a screening of the parameters (see Table S3), the reaction conditions were fixed to $175^{\circ} \mathrm{C}, 10 \mathrm{bar} \mathrm{H}_{2}$, and 0.5 $\mathrm{mL} \cdot \mathrm{min}^{-1}$ (residence time $=1 \mathrm{~min}$ ).

High conversion (75-85\%) and selectivity (85-95\%) corresponding to a nearly constant yield of ca. $70 \%$ toward the formation of 1a were maintained over a period of $6 \mathrm{~h}$ without any noticeable decay (Figure 5). TEM characterization of the catalyst after $6 \mathrm{~h}$ on stream did not show a significant change in the size and dispersion of the Ru NPs $(1.9 \pm 0.4 \mathrm{~nm}$; Figure S7). In addition, ICP measurements did not evidence any leaching of the metals ( $\mathrm{Ru}$ and $\mathrm{Zn}$ ) or of the IL, and the textural properties of the catalyst were conserved according to BET analysis (Table S4). These results indicate that Ru@
SILP- $\left[\mathrm{ZnCl}_{4}\right]^{2-}$ is active, selective, and highly stable for the hydrogenation of benzofuran in continuous flow conditions.

The catalytic study with $\mathrm{Ru} @ S I L P-\left[\mathrm{ZnCl}_{4}\right]^{2-}$ was further pursued by exploring the substrate scope of this reaction considering various functionalized benzofurans (Table 1). A nonfunctionalized Ru@SILP catalyst (Ru NPs immobilized on an imidazolium-based SILP with $\mathrm{NTf}_{2}$ as anion, see Figure S8 for details) was used for comparison.

Using Ru@SILP- $\left[\mathrm{ZnCl}_{4}\right]^{2-}$, benzofuran derivatives with electron-donating (substrates 2 and 3 ) and electron-withdrawing (4 and 5) substituents on the six-membered ring were hydrogenated as selectively as benzofuran (1), giving the corresponding dihydrobenzofurans products in more than $90 \%$ yield (85-90\% isolated yields). Introducing a methyl group in positions 2 and 3 on the furan ring ( 6 and 7 ) made the hydrogenation slightly more challenging, but good yields ( 80 and $75 \%$, respectively) could still be obtained after adapting the reaction conditions. Interestingly, Ru@SILP- $\left[\mathrm{ZnCl}_{4}\right]^{2-}$ was also able to hydrogenate very selectively bergapten (8), a natural psoralen derivative employed in several biomedical applications, ${ }^{39,40}$ giving product $\mathbf{8 a}$ with excellent selectivity (96\%) in high yield (95\% NMR yield, $84 \%$ isolated yield). In contrast, hydrogenation of substrates 1-8 with Ru@SILP resulted in all cases in lower conversions and/or selectivities toward the formation of the desired products, outlining the importance of the combination of Ru NPs and Lewis acid sites. This was further confirmed with the use of a commercial $\mathrm{Ru} / \mathrm{C}$ catalyst for the hydrogenation of substrate 3 , which also gave a significantly lower yield for the product 3a (62 vs $85 \%$ isolated yield, Table S5).

Using Ru@SILP-[ $\left.\mathrm{ZnCl}_{4}\right]^{2-}$, all the substrates considered were selectively hydrogenated, whereas the C6-membered aromatic ring was conserved, showing that the catalyst can accommodate a wide range of functionalities. In addition, time profiles performed with Ru@SILP and Ru@SILP-[ $\left.\mathrm{ZnCl}_{4}\right]^{2-}$ using benzofuran as the substrate show that the presence of the Lewis acid does not only hinder the hydrogenation of arenes, but also accelerates the hydrogenation of the furan moiety (Figure 6).

The versatility of the $\mathrm{Ru} @ S I L P-\left[\mathrm{ZnCl}_{4}\right]^{2-}$ catalyst was further studied in continuous flow operation. Solutions containing substrate $\mathbf{1}$ or $\mathbf{3}$ were alternatively passed in a hydrogen stream over the catalyst bed using a $\mathrm{H}$-Cube Pro continuous flow system from ThalesNano. Substrate 1 was used for $2 \mathrm{~h}$ before switching to substrate 3 that was kept as well for $2 \mathrm{~h}$. This substrate "switch" was performed three times in a row to study the impact of real-time repeated substrate changes on the catalyst's properties (Figure 7). Under optimized reaction conditions (see Table S6 for optimization steps), the substrate feed could be switched back and forth between substrates $\mathbf{1}$ and $\mathbf{3}$ to alternatively produce $\mathbf{1 a}$ and $\mathbf{3 a}$ in more than $70 \%$ yield. The consecutive $2 \mathrm{~h}$ cycles corresponded to a total of $12 \mathrm{~h}$ time-on-stream without significant changes in activity, selectivity, or stability of the catalyst, outlining once again its robustness and versatility in the hydrogenation of benzofuran derivatives.

\section{CONCLUSIONS}

A Lewis acidic-supported ionic liquid phase material (SILPLA) was synthesized and used as support for ruthenium NPs ( $\mathrm{Ru}$ NPs) deposited from organometallic precursors. The resulting material was fully characterized, revealing the formation of small and well-dispersed Ru NPs on the support, 
Table 1. Selective Hydrogenation of Benzofuran Derivatives Catalyzed by $\mathrm{Ru} @ S I L P-\left[\mathrm{ZnCl}_{4}\right]^{2-a, b}$

\begin{tabular}{|c|c|c|c|c|c|c|c|c|c|c|c|}
\hline \multirow[b]{3}{*}{ Ent. } & \multirow[b]{3}{*}{ Substrate } & \multicolumn{10}{|c|}{$\mathrm{R}_{1}=\mathrm{H}, \mathrm{Me}, \mathrm{OMe}, \mathrm{Cl}, \mathrm{COOMe} ; \mathrm{R}_{2}=\mathrm{H}, \mathrm{Me}$} \\
\hline & & & & & & \multicolumn{3}{|c|}{ Ru@SILP } & \multicolumn{3}{|c|}{$\begin{array}{c}\mathrm{Ru} @ \mathrm{SILP}_{\left[\mathrm{ZnCl}_{4}\right]^{2-}} \\
\text { - }\end{array}$} \\
\hline & & $\begin{array}{c}\mathbf{T} \\
{ }^{\circ} \mathrm{C}\end{array}$ & $\begin{array}{c}\mathbf{P} \\
\text { Bar }\end{array}$ & $\begin{array}{c}\text { Sub. } \\
\text { Eq. }\end{array}$ & Product & $\begin{array}{c}\mathbf{X} \\
(\%)\end{array}$ & $\begin{array}{c}\mathbf{S} \\
(\%)\end{array}$ & $\begin{array}{c}\mathbf{Y} \\
(\%)\end{array}$ & $\begin{array}{c}\mathbf{X} \\
(\%)\end{array}$ & $\begin{array}{c}\mathbf{S} \\
(\%)\end{array}$ & $\begin{array}{c}\mathbf{Y} \\
(\%)\end{array}$ \\
\hline 1 & & 150 & 10 & 750 & & 81 & 87 & 71 & 97 & 90 & 88 \\
\hline 2 & & 150 & 10 & 750 & & 42 & 95 & 40 & $>99$ & 93 & 93 \\
\hline 3 & & 120 & 20 & 750 & & 57 & 96 & 55 & $>99$ & 95 & $\begin{array}{c}95 \\
(85)\end{array}$ \\
\hline 4 & 4 & 130 & 30 & 250 & $4 a$ & 75 & 96 & 72 & 98 & 93 & $\begin{array}{c}91 \\
(86)\end{array}$ \\
\hline 5 & & 130 & 10 & 250 & & $>99$ & 60 & 60 & $>99$ & 95 & $\begin{array}{c}95 \\
(90)\end{array}$ \\
\hline 0 & & 175 & 10 & 500 & & 83 & 78 & 65 & 88 & 91 & 80 \\
\hline 7 & & 150 & 10 & 500 & & 20 & 5 & 1 & $81^{[\mathrm{c}]}$ & 93 & 75 \\
\hline 8 & 8 & 80 & 50 & 250 & & $>99^{[\mathrm{d}}$ & 66 & $66^{[\mathrm{e}]}$ & $>99^{[\mathrm{d}]}$ & 96 & $\begin{array}{l}95^{[\mathrm{e}]} \\
(84)\end{array}$ \\
\hline
\end{tabular}

${ }^{a}$ Results obtained using Ru@SILP are given for comparison. ${ }^{b}$ Reaction conditions: Ru@SILP-[ $\left.\mathrm{ZnCl}_{4}\right]^{2-}(75 \mathrm{mg}, 0.00224 \mathrm{mmol} \mathrm{Ru})$, decalin $(0.5$ $\mathrm{mL}), 16 \mathrm{~h} .{ }^{c} 24 \mathrm{~h} .{ }^{d}$ 1,4-dioxane $(1.0 \mathrm{~mL}), 32 \mathrm{~h}$. Composition of the reaction mixture determined by GC using tetradecane as an internal standard. ${ }^{e}$ Composition of the reaction mixture determined by NMR using mesitylene as a standard. $(\mathrm{X}=$ conversion $/ \mathrm{S}=$ selectivity $/ \mathrm{Y}=$ yield $)$. Isolated yields are given in parentheses.
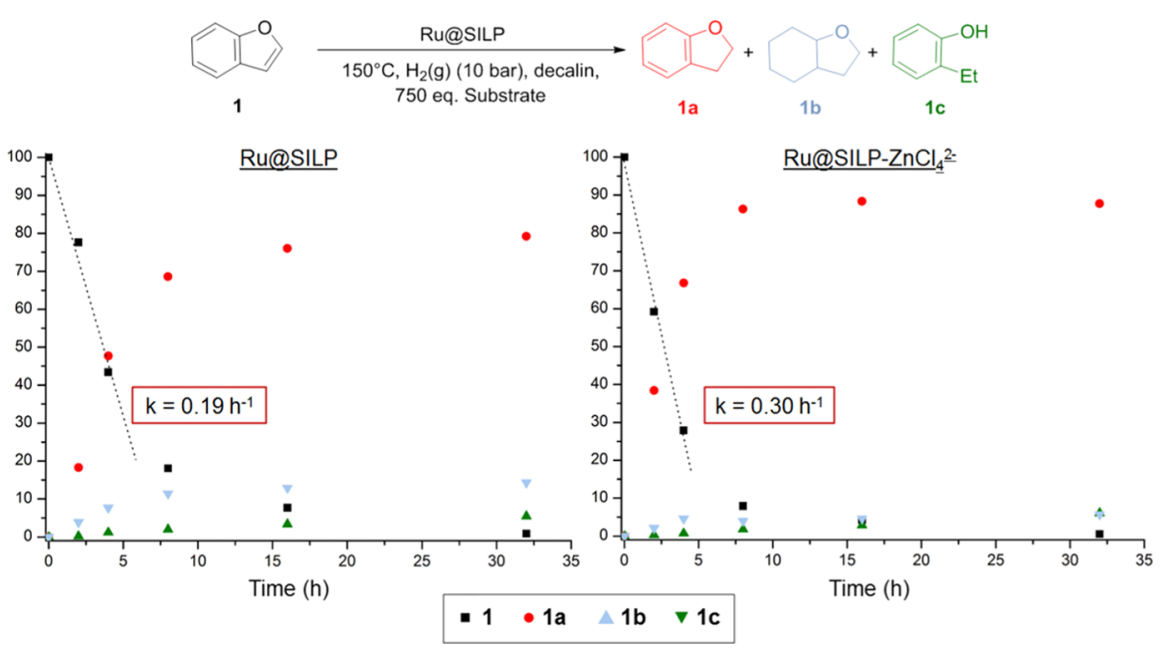

Figure 6. Comparative rate studies for the hydrogenation of benzofuran (1) using Ru@SILP and Ru@SILP-ZnCl ${ }_{4}^{2-}$. Catalyst (75 mg, 0.00224 $\mathrm{mmol} \mathrm{Ru})$, substrate $\left(1.68 \mathrm{mmol}, 750\right.$ equiv), decalin $(0.5 \mathrm{~mL}), \mathrm{H}_{2}(10 \mathrm{bar}), 150{ }^{\circ} \mathrm{C}$. Composition of the reaction mixture determined by GC using tetradecane as an internal standard.

in close interaction with the chlorozincate species. XPS analysis shows that the NPs are in the metallic state, and suggestsbased on previous literature reports-that the chlorozincate species consist predominantly of $\left[\mathrm{ZnCl}_{4}\right]^{2-}$ anions. The $\mathrm{Ru} @$ SILP- $\left[\mathrm{ZnCl}_{4}\right]^{2-}$ catalyst was applied for the hydrogenation of benzofuran derivatives, and was found to be highly active, 

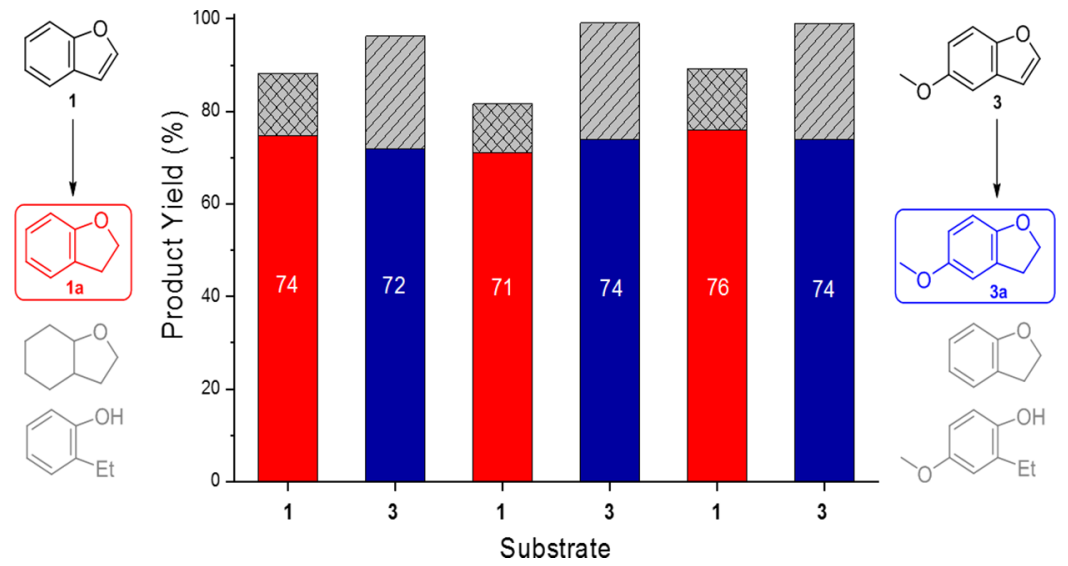

Figure 7. Ru@SILP- $\left[\mathrm{ZnCl}_{4}\right]^{2-}(520 \mathrm{mg}, 0.016 \mathrm{mmol} \mathrm{Ru})$ under continuous flow conditions for the hydrogenation of benzofuran $\left(175{ }^{\circ} \mathrm{C}, 10 \mathrm{bar}\right.$ $\mathrm{H}_{2}, 0.05 \mathrm{M}$ in decalin, $0.5 \mathrm{~mL} \cdot \mathrm{min}^{-1}$, residence time $\left.=1 \mathrm{~min}\right)$ and 5-methoxybenzofuran $\left(175^{\circ} \mathrm{C}, 20 \mathrm{bar} \mathrm{H}_{2}, 0.0125 \mathrm{M}\right.$ in decalin, $0.5 \mathrm{~mL} \cdot \mathrm{min}^{-1}$, residence time $=1 \mathrm{~min}$ ), gas flow rate $=35 \mathrm{~N} \mathrm{~mL} \cdot \mathrm{min}^{-1}$.

selective, and stable for the selective hydrogenation of a broad range of substrates and functional groups. Under continuous flow conditions, benzofuran and 5-methoxybenzofuran could be hydrogenated alternatingly over the same catalysts to produce the corresponding partially hydrogenated products in good yields. This demonstrates the versatility of the Ru@SILP$\left[\mathrm{ZnCl}_{4}\right]^{2-}$ catalytic system and its potential for the production of dihydrobenzofuran derivatives under synthetically relevant conditions. The molecular approach to the catalyst synthesis is modular and flexible, providing general access to M@SILP-LA systems. The results further substantiate the possibility to utilize this methodology for the preparation of finely tuned multifunctional catalysts to achieve challenging selectivities in hydrogenation reactions.

\section{ASSOCIATED CONTENT}

\section{(s) Supporting Information}

The Supporting Information is available free of charge at https://pubs.acs.org/doi/10.1021/acscatal.9b05124.

Complete synthesis, characterization, and catalysis data for Ru@SILP-LA (PDF)

\section{AUTHOR INFORMATION}

\section{Corresponding Author}

Walter Leitner - Institut für Technische und Makromolekulare Chemie, RWTH Aachen University, Aachen 52074, Germany; Max Planck Institute for Chemical Energy Conversion, Mülheim an der Ruhr 45470, Germany; 이이.org/0000-0001-61009656; Email: walter.leitner@cec.mpg.de

\section{Authors}

Sami El Sayed - Institut für Technische und Makromolekulare Chemie, RWTH Aachen University, Aachen 52074, Germany

Alexis Bordet - Max Planck Institute for Chemical Energy Conversion, Mülheim an der Ruhr 45470, Germany; (1) orcid.org/0000-0003-0133-3416

Claudia Weidenthaler - Max-Planck-Institut für Kohlenforschung, Mülheim an der Ruhr 45470, Germany

Walid Hetaba - Max Planck Institute for Chemical Energy Conversion, Mülheim an der Ruhr 45470, Germany; Fritz Haber Institute of the Max Planck Society, Berlin 14195, Germany
Kylie L. Luska - Institut für Technische und Makromolekulare Chemie, RWTH Aachen University, Aachen 52074, Germany

Complete contact information is available at:

https://pubs.acs.org/10.1021/acscatal.9b05124

\section{Notes}

The authors declare no competing financial interest.

\section{ACKNOWLEDGMENTS}

The authors acknowledge financial support by the Max Planck Society and by the Deutsche Forschungsgemeinschaft (DFG, German Research Foundation) under Germany's Excellence Strategy-Exzellenzcluster 2186 "The Fuel Science Center" ID: 390919832. Furthermore, the authors would like to thank Josef Vaeßen (ITMC, RWTH Aachen) for BET absorption measurements, Hannelore Eschmann and Elke Biener (ITMC, RWTH Aachen) for GC measurements, Meike Emondts (ITMC, RWTH Aachen) for solid-state NMR measurements, Norbert Pfänder (MPI for Chemical Energy Conversion, Mülheim an der Ruhr), Adrian Schlüter (MPI for Kohlenforschung, Mülheim an der Ruhr) for TEM analysis, and Rosalie Dalhoff, Konstantin Kröckert and David Kuß (ITMC, RWTH Aachen) for their help for the experimental study.

\section{REFERENCES}

(1) Wang, Y.; Huang, Z.; Leng, X.; Zhu, H.; Liu, G.; Huang, Z. Transfer Hydrogenation of Alkenes Using Ethanol Catalyzed by a NCP Pincer Iridium Complex: Scope and Mechanism. J. Am. Chem. Soc. 2018, 140, 4417-4429.

(2) Ji, P.; Song, Y.; Drake, T.; Veroneau, S. S.; Lin, Z.; Pan, X.; Lin, W. Titanium(III)-Oxo Clusters in a Metal-Organic Framework Support Single-Site Co(II)-Hydride Catalysts for Arene Hydrogenation. J. Am. Chem. Soc. 2018, 140, 433-440.

(3) Jiang, H.-y.; Zhang, S.-S.; Sun, B. Highly Selective Hydrogenation with Ionic Liquid Stabilized Nickel Nanoparticles. Catal. Lett. 2018, 148, 1336-1344.

(4) Ye, T.-N.; Li, J.; Kitano, M.; Hosono, H. Unique Nanocages of $12 \mathrm{CaO} .7 \mathrm{Al}_{2} \mathrm{O}_{3}$ Boost Heterolytic Hydrogen Activation and Selective Hydrogenation of Heteroarenes over Ruthenium Catalyst. Green Chem. 2017, 19, 749-756.

(5) Karakulina, A.; Gopakumar, A.; Akçok, I.; Roulier, B. L.; LaGrange, T.; Katsyuba, S. A.; Das, S.; Dyson, P. J. A Rhodium Nanoparticle-Lewis Acidic Ionic Liquid Catalyst for the Chemoselective Reduction of Heteroarenes. Angew. Chem., Int. Ed. 2016, 55, 292-296. 
(6) Luska, K. L.; Bordet, A.; Tricard, S.; Sinev, I.; Grünert, W.; Chaudret, B.; Leitner, W. Enhancing the Catalytic Properties of Ruthenium Nanoparticle-SILP Catalysts by Dilution with Iron. ACS Catal. 2016, 6, 3719-3726.

(7) Offner-Marko, L.; Bordet, A.; Moos, G.; Tricard, S.; Rengshausen, S.; Chaudret, B.; Luska, K. L.; Leitner, W. Bimetallic Nanoparticles in Supported Ionic Liquid Phases as Multifunctional Catalysts for the Selective Hydrodeoxygenation of Aromatic Substrates. Angew. Chem., Int. Ed. 2018, 57, 12721-12726.

(8) Ortega, N.; Urban, S.; Beiring, B.; Glorius, F. Ruthenium NHC Catalyzed Highly Asymmetric Hydrogenation of Benzofurans. Angew. Chem., Int. Ed. 2012, 51, 1710-1713.

(9) Adam, R.; Cabrero-Antonino, J. R.; Spannenberg, A.; Junge, K.; Jackstell, R.; Beller, M. A General and Highly Selective CobaltCatalyzed Hydrogenation of N-Heteroarenes under Mild Reaction Conditions. Angew. Chem., Int. Ed. 2017, 56, 3216-3220.

(10) Wang, D.-S.; Chen, Q.-A.; Lu, S.-M.; Zhou, Y.-G. Asymmetric Hydrogenation of Heteroarenes and Arenes. Chem. Rev. 2012, 112, 2557-2590.

(11) Karakulina, A.; Gopakumar, A.; Fei, Z.; Dyson, P. J. Chemoselective Reduction of Heteroarenes with a Reduced Graphene Oxide Supported Rhodium Nanoparticle Catalyst. Catal. Sci. Technol. 2018, 8, 5091-5097.

(12) Wei, Z.; Chen, Y.; Wang, J.; Su, D.; Tang, M.; Mao, S.; Wang, Y. Cobalt Encapsulated in N-Doped Graphene Layers: An Efficient and Stable Catalyst for Hydrogenation of Quinoline Compounds. ACS Catal. 2016, 6, 5816-5822.

(13) Jiang, H.-y.; Xu, J.; Sun, B. Selective Hydrogenation of Aromatic Compounds Using Modified Iridium Nanoparticles. Appl. Organomet. Chem. 2018, 32, No. e4260.

(14) Huang, X.-X.; Zhou, C.-C.; Li, L.-Z.; Peng, Y.; Lou, L.-L.; Liu, S.; Li, D.-M.; Ikejima, T.; Song, S.-J. Cytotoxic and Antioxidant Dihydrobenzofuran Neolignans from the Seeds of Crataegus Pinnatifida. Fitoterapia 2013, 91, 217-223.

(15) Cardullo, N.; Pulvirenti, L.; Spatafora, C.; Musso, N.; Barresi, V.; Condorelli, D. F.; Tringali, C. Dihydrobenzofuran Neolignanamides: Laccase-Mediated Biomimetic Synthesis and Antiproliferative Activity. J. Nat. Prod. 2016, 79, 2122-2134.

(16) Sun, J.; Zhou, W.; Wei, C.-X.; Zhang, Z.; Jin, X.; Li, G. A New Benzofuran from Artemisia Halodendron Turcz. Ex Bess. Nat. Prod. Res. 2019, 33, 226-232.

(17) Lee, S.; Song, I.-H.; Lee, J.-H.; Yang, W.-Y.; Oh, K.-B.; Shin, J. Sortase a Inhibitory Metabolites from the Roots of Pulsatilla Koreana. Bioorg. Med. Chem. Lett. 2014, 24, 44-48.

(18) Baumgartner, L.; Sosa, S.; Atanasov, A. G.; Bodensieck, A.; Fakhrudin, N.; Bauer, J.; Favero, G. D.; Ponti, C.; Heiss, E. H.; Schwaiger, S.; Ladurner, A.; Widowitz, U.; Loggia, R. D.; Rollinger, J. M.; Werz, O.; Bauer, R.; Dirsch, V. M.; Tubaro, A.; Stuppner, H. Lignan Derivatives fromKrameria lappaceaRoots Inhibit Acute Inflammation in Vivo and Pro-inflammatory Mediators in Vitro. J. Nat. Prod. 2011, 74, 1779-1786.

(19) Di Micco, S.; Spatafora, C.; Cardullo, N.; Riccio, R.; Fischer, K.; Pergola, C.; Koeberle, A.; Werz, O.; Chalal, M.; VervandierFasseur, D.; Tringali, C.; Bifulco, G. 2,3-Dihydrobenzofuran Privileged Structures as New Bioinspired Lead Compounds for the Design of mPGES-1 Inhibitors. Bioorg. Med. Chem. 2016, 24, 820826.

(20) Xie, L.; Dong, S.; Zhang, Q.; Feng, X.; Liu, X. Asymmetric Construction of Dihydrobenzofuran-2,5-Dione Derivatives Via Desymmetrization of P-Quinols with Azlactones. Chem. Commun. 2019, 55, 87-90.

(21) Jiang, H.-Y.; Zheng, X.-X. Phosphine-Functionalized Ionic Liquid-Stabilized Rhodium Nanoparticles for Selective Hydrogenation of Aromatic Compounds. Appl. Catal., A 2015, 499, 118-123.

(22) Ji, P.; Manna, K.; Lin, Z.; Urban, A.; Greene, F. X.; Lan, G.; Lin, W. Single-Site Cobalt Catalysts at New $\mathrm{Zr}_{8}\left(\mu_{2}-\mathrm{O}\right)_{8}\left(\mu_{2}-\mathrm{OH}\right)_{4}$ MetalOrganic Framework Nodes for Highly Active Hydrogenation of Alkenes, Imines, Carbonyls, and Heterocycles. J. Am. Chem. Soc. 2016, 138, 12234-12242.
(23) Chen, L.; Fink, C.; Fei, Z.; Dyson, P. J.; Laurenczy, G. An efficient Pt nanoparticle-ionic liquid system for the hydrodeoxygenation of bio-derived phenols under mild conditions. Green Chem. 2017, 19, 5435-5441.

(24) Chacón, G.; Dupont, J. Arene Hydrogenation by Metal Nanoparticles in Ionic Liquids. Chem CatChem 2019, 11, 333-341.

(25) Foppa, L.; Luza, L.; Gual, A.; Weibel, D. E.; Eberhardt, D.; Teixeira, S. R.; Dupont, J. Sputtering-Deposition of Ru Nanoparticles onto $\mathrm{Al}_{2} \mathrm{O}_{3}$ Modified with Imidazolium Ionic Liquids: Synthesis, Characterisation and Catalysis. Dalton Trans. 2015, 44, 2827-2834.

(26) Rengshausen, S.; Etscheidt, F.; Großkurth, J.; Luska, K.; Bordet, A.; Leitner, W. Catalytic Hydrogenolysis of Substituted Diaryl Ethers by Using Ruthenium Nanoparticles on an Acidic Supported Ionic Liquid Phase (Ru@SILP-SO 3 H). Synlett 2019, 30, 405-412.

(27) Luska, K. L.; Migowski, P.; Leitner, W. Ionic Liquid-Stabilized Nanoparticles as Catalysts for the Conversion of Biomass. Green Chem. 2015, 17, 3195-3206.

(28) Riisager, A.; Eriksen, K. M.; Wasserscheid, P.; Fehrmann, R. Propene and 1-Octene Hydroformylation with Silica-Supported, Ionic Liquid-Phase (SILP) Rh-Phosphine Catalysts in Continuous FixedBed Mode. Catal. Lett. 2003, 90, 149-153.

(29) Riisager, A.; Wasserscheid, P.; van Hal, R.; Fehrmann, R. Continuous Fixed-Bed Gas-Phase Hydroformylation Using Supported Ionic Liquid-Phase (SILP) Rh Catalysts. J. Catal. 2003, 219, 452455.

(30) Luska, K. L.; Julis, J.; Stavitski, E.; Zakharov, D. N.; Adams, A.; Leitner, W. Bifunctional nanoparticle-SILP catalysts (NPs@SILP) for the selective deoxygenation of biomass substrates. Chem. Sci. 2014, 5, 4895-4905.

(31) Luska, K. L.; Migowski, P.; El Sayed, S.; Leitner, W. Synergistic Interaction within Bifunctional Ruthenium Nanoparticle/SILP Catalysts for the Selective Hydrodeoxygenation of Phenols. Angew. Chem., Int. Ed. 2015, 54, 15750-15755.

(32) Lecocq, V.; Graille, A.; Santini, C. C.; Baudouin, A.; Chauvin, Y.; Basset, J. M.; Arzel, L.; Bouchu, D.; Fenet, B. Synthesis and Characterization of Ionic Liquids Based Upon 1-Butyl-2,3-Dimethylimidazolium Chloride/ $\mathrm{ZnCl}_{2}$. New J. Chem. 2005, 29, 700-706.

(33) Dupont, J.; Suarez, P. A. Z.; Umpierre, A. P.; de Souza, R. F. Organo-zincate molten salts as immobilising agents for organometallic catalysis. Catal. Lett. 2001, 73, 211-213.

(34) Taylor, A. W.; Men, S.; Clarke, C. J.; Licence, P. Acidity and Basicity of Halometallate-Based Ionic Liquids from X-Ray Photoelectron Spectroscopy. RSC Adv. 2013, 3, 9436-9445.

(35) Estager, J.; Nockemann, P.; Seddon, K. R.; Swadźba-Kwaśny, M.; Tyrrell, S. Validation of Speciation Techniques: A Study of Chlorozincate(II) Ionic Liquids. Inorg. Chem. 2011, 50, 5258-5271.

(36) Estager, J.; Holbrey, J. D.; Swadźba-Kwaśny, M. Halometallate ionic liquids - revisited. Chem. Soc. Rev. 2014, 43, 847-886.

(37) Aiken, J. D., III; Finke, R. G. A review of modern transitionmetal nanoclusters: their synthesis, characterization, and applications in catalysis. J. Mol. Catal. A: Chem. 1999, 145, 1-44.

(38) Bönnemann, H.; Richards, R. M. Nanoscopic Metal Particles Synthetic Methods and Potential Applications. Eur. J. Inorg. Chem. 2001, 2001, 2455-2480.

(39) De Amicis, F.; Aquila, S.; Morelli, C.; Guido, C.; Santoro, M.; Perrotta, I.; Mauro, L.; Giordano, F.; Nigro, A.; Ando, S.; Panno, M. L. Bergapten Drives Autophagy through the up-Regulation of PTEN Expression in Breast Cancer Cells. Mol. Cancer 2015, 14, 130.

(40) Panno, M. L.; Giordano, F.; Mastroianni, F.; Palma, M. G.; Bartella, V.; Carpino, A.; Aquila, S.; Andò, S. Breast Cancer Cell Survival Signal Is Affected by Bergapten Combined with an Ultraviolet Irradiation. FEBS Lett. 2010, 584, 2321-2326. 